\title{
A Method for the reduction of MIMO systems using Interlacing Property and Coefficients Matching
}

\author{
P.Rama Jaya Lakshmi \\ Research Scholar,Dept.of Chemical Engg \\ M.E. student,Dept. of Electrical \\ A.U.College of Engineering(A), \\ Andhra University \\ Visakhapatnam,A.P., \\ P.Mallikarjuna Rao \\ Professor, Dept. of electrical engineering \\ A.U.College of Engineering (A), \\ Andhra University \\ Visakhapatnam,A.P,
}

\author{
Ch.Vishnu Chakravarti \\ M.E. student,Dept. of Electrical \\ A.U.College of Engineering(A), \\ Visakhapatnam,A.P.,
}

\begin{abstract}
This paper suggests a mixed method for the reduction of order of linear high order MIMO systems. This method is based upon the interlacing property of the systems. The denominator polynomial of the reduced order model is obtained by using interlacing property and the numerator is obtained by matching the coefficients of higher order system with those of denominator of the reduced order model. In general the stability of the higher order system is retained in their models. This method is very much flexible and it avoids the iterative procedures for obtaining stable reduced models for a stable high order MIMO systems. The suggested method gives good approximation of the response characteristics of High order MIMO system and its model.
\end{abstract}

\section{Index terms:}

Large Scale Systems, Order Reduction, Interlacing property, MIMO Systems

\section{INTRODUCTION}

Since recent years Design, Control and Analysis of large scale systems is emerging as an essential area of research. Involvement of large number of variables in the high order system makes the design and analysis process computationally tedious. Majority of available analysis and design methods fail to give reasonable results when applied to large-scale systems. At this juncture the advantageous features of order reduction make the application of reduction procedures inevitable. The order reduction procedures are mainly classified in to either time domain or frequency domain. Basing on the simplicity and amicability the frequency domain dependent methods have become more prominent. Polynomial reduction methods are one of the important groups in the frequency domain category. The coefficients of the reduced order transfer function are generated using various classical theories of mathematical approximations etc. like Routh approximation, Pade, Continued fraction approximation etc. The method "Routh approximations for reduction of LTI systems"[1] Suggested by Hutton and fried land is one of the prominent methods in the Routh approximation group. "Model reduction by condensed continued fraction method" is given by T. N. Lucas. Shamash has suggested important methods using continued fraction expansion method [4]. Unfortunately, very few methods are available for the reduction of Linear MIMO systems. Many of the methods available in the international literature can be easily extended for the reduced of linear MIMO (Multi input -Multi output systems). Earlier a method for the reduction MIMO methods was given by Bendekas et.at.,[5], which is mixed method of time moment matching and Pade approximates. Taiwoet.al.,[6] developed methods based upon Pade approximated generalized time moments. Chen [7] has given a method based on matrix continued fraction technique. The Routh approximation method given by Huttom [1], was extended to MIMO systems by Sinha [8]

This paper suggests a mixed method for the reduction of large scale linear MIMO systems. The denominator polynomial of the reduced order model is obtained by using the interlacing property of the polynomials and the numerator polynomial is obtained by using matching of coefficients higher order system and its model. This method in general retains the stability of higher order system in its model in addition to the matching of time response characteristics of the original high order system. This method is purely numerical and consists of non iterative procedure and can easily be implemented using a digital computer. Numerical examples are presented to show the effectiveness of proposed procedure.

\section{II.PROBLEM FORMULATION}

Consider an MIMO system, given as

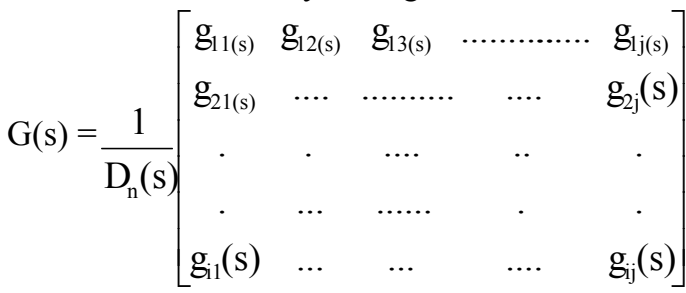

Where

$\mathrm{i}=1,2,3 \ldots \ldots \ldots \ldots, \mathrm{j}=1,2,3, \ldots \ldots \ldots$ 


$$
\begin{aligned}
& \mathrm{D}_{\mathrm{n}}(\mathrm{s})=\sum_{\mathrm{l}=0}^{\mathrm{n}}\left[\mathrm{A}_{1}\right] \mathrm{S}^{1} \\
& \mathrm{~g}_{\mathrm{ij}}(\mathrm{s})=\sum_{\mathrm{l}=0}^{\mathrm{n}-1}\left[\mathrm{~B}_{\mathrm{ij}}\right] \mathrm{S}_{1} \mathrm{~S}^{1} \\
& \therefore \mathrm{G}_{\mathrm{ij}}(\mathrm{s})=\frac{\sum_{\mathrm{l}=0}^{\mathrm{n}-1}\left[\mathrm{~B}_{\mathrm{ij}}\right] \mathrm{S}_{1} \mathrm{~S}^{\mathrm{n}}\left[\mathrm{A}_{1}\right] \mathrm{S}^{1}}{\sum_{\mathrm{l}=0}}
\end{aligned}
$$

The reduced order model can be represented as,

$$
\mathrm{R}_{\mathrm{ij}}(\mathrm{s})=\frac{\sum_{\mathrm{l}=0}^{\mathrm{K}-1}\left[\mathrm{~b}_{\mathrm{ij}}\right] \mathrm{l}_{\mathrm{l}}^{\mathrm{l}}}{\sum_{\mathrm{l}=0}^{\mathrm{k}}\left[\mathrm{a}_{\mathrm{l}}\right] \mathrm{s}^{\mathrm{l}}}
$$

Where

$\mathrm{i}=1,2,3 \ldots \mathrm{K} ; \mathrm{j}=1,2,3 \ldots \mathrm{K}$

Let the transfer function of a higher order linear time invariant stable plant is given by

$\mathrm{G}_{11}(\mathrm{~S})=\frac{N(s)}{D(s)}=\frac{B_{0}+B S+B_{2} S^{2}+\ldots \ldots \ldots \ldots \ldots+B_{n} S^{n}}{A_{0}+A_{1} S+A_{2} S^{2}+\ldots \ldots \ldots \ldots \ldots+A_{n} S^{n-1}}$

The objective is to obtain the $\mathrm{k}^{\mathrm{th}}$ order reduced order model. The respective procedural steps are as follows:

Step1: The Denominator polynomial is separated into even and odd parts.

For $\mathrm{n}$ is even:

$\mathrm{D}^{\text {even }}(\mathrm{S})=\mathrm{A}_{0}+\mathrm{A}_{2} \mathrm{~s}^{2}+\mathrm{A}_{4} \mathrm{~s}^{4}+\ldots \ldots+\mathrm{A}_{n} \mathrm{~s}^{n}$

$\frac{D^{\text {odd }}(S)}{S}=\mathrm{A}_{1}+\mathrm{A}_{3} \mathrm{~s}^{2}+\mathrm{A}_{5} \mathrm{~s}^{4}+\ldots \ldots \ldots \ldots \ldots \ldots \ldots \ldots+\mathrm{A}$

$(n-1) \mathrm{S}^{(n-2)}$

For $\mathrm{n}$ is odd:

$\mathrm{D}(\mathrm{S})=\mathrm{A}_{0}+\mathrm{A}_{2} \mathrm{~s}^{2}+\mathrm{A}_{4} \mathrm{~s}^{4}+\ldots \ldots .+\mathrm{A}_{(n-1)} \mathrm{s}^{(n-1)}$

$\frac{D^{\text {odd }}(S)}{S}=\mathrm{A}_{1}+\mathrm{A}_{3} \mathrm{~s}^{2}+\mathrm{A}_{5} \mathrm{~s}^{4}+\ldots \ldots \ldots \ldots \ldots \ldots \ldots+\mathrm{A}$

(n) $\mathrm{S}^{(n-1)}$
Let $\left(0 \pm \omega^{d}{ }_{e, i}\right)$ and $\left(0 \pm \omega^{d}{ }_{o, i}\right)$ denotes the roots of $\mathrm{D}^{\text {even }}(\mathrm{S})$ and $\frac{D^{\text {odd }}(S)}{S}$ respectively. Then, it can be observed that

$0<\omega_{d, 1}^{e}<\omega_{d, 1}^{o}<\omega_{d, 2}^{e}<\omega_{d, 2}^{o}<\omega_{d, 3}^{e} \ldots \ldots$

Step2:

The Denominator polynomial of the $\mathrm{k}^{\text {th }}$ order reduced order model is obtained as,

The even and odd polynomial for the reduced order polynomial can be written as,

For $\mathrm{k}$ is even:

$\mathrm{D} k^{\text {even }}(\mathrm{S})=\left(\mathrm{s}^{2}+\omega_{e, 1}^{2}\right)\left(\mathrm{s}^{2}+\omega_{e, 2}^{2}\right)$

$\ldots\left(\mathrm{s}^{2}+\omega_{e,(k / 2)}^{2}\right)$

$\frac{D_{k}^{o d d}(S)}{S}=\left(\mathrm{s}^{2}+\omega_{o, 1}^{2}\right)\left(\mathrm{s}^{2}+\omega_{o, 2}^{2}\right)$

$\mathrm{s}^{2}+\omega_{o,(k / 2)-1)}^{2}$

For $\mathrm{k}$ is odd:

$\mathrm{D}_{k}{ }^{\text {even }}(\mathrm{S})=\left(\mathrm{s}^{2}+\omega_{e, 1}^{2}\right)\left(\mathrm{s}^{2}+\omega_{e, 2}^{2}\right) \ldots \ldots \ldots \ldots$

.......... $\left(\mathrm{s}^{2}+\omega^{2} e,(k-1) / 2\right) \quad \ldots(7)$

$\frac{D_{k}^{o d d}(S)}{S}=\left(\mathrm{s}^{2}+\omega_{o, 1}^{2}\right)\left(\mathrm{s}^{2}+\omega_{o, 2}^{2}\right) \ldots \ldots \ldots \ldots \ldots$

........ $\left(\mathrm{s}^{2}+\omega_{o,(k-1) / 2}^{2}\right)$

Modified reduced denominators are

$\mathrm{D}_{m}{ }^{\text {even }}(\mathrm{S})=\mathrm{I}_{1} * \mathrm{D}_{\mathrm{k}}{ }^{\text {even }}(\mathrm{S})$

$\mathrm{D}_{m}{ }^{\text {odd }}(\mathrm{S})=\mathrm{I}_{2} * \mathrm{D}_{\mathrm{k}}{ }^{\text {odd }}(\mathrm{S})$

Now

$\mathrm{D}_{k}(\mathrm{~S})=\mathrm{D}_{\mathrm{m}}{ }^{\text {even }}(\mathrm{S})+\mathrm{D}_{\mathrm{m}}{ }^{\text {odd }}(\mathrm{S})$

Step3: The Numerator polynomial

$\mathrm{N}_{\mathrm{k}}(\mathrm{S})=\sum_{\mathrm{l}=0}^{\mathrm{k}-1}\left[\mathrm{a}_{\mathrm{ij}}\right] \mathrm{S}_{\mathrm{l}}$

of the reduced order model is obtained by using eqn.

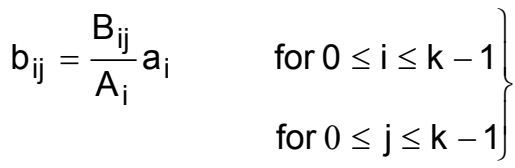

Step4: Finally the $\mathrm{k}^{\text {th }}$ order reduced model is obtained as 


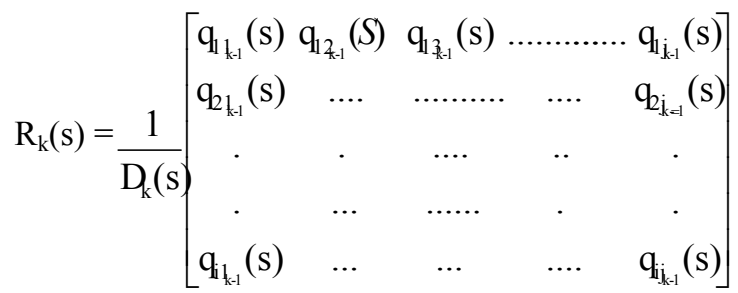

Where

$\mathrm{i}=1,2, . \mathrm{k}-1 \ldots ; \mathrm{j}=1,2, . \mathrm{k}-1$

$R_{k}(s)=\frac{N_{k}(s)}{D_{k}(s)}$

Step5: similarly the remaining reduced order systems one obtained by using above steps .the reduced order model can be represented as,

$\mathrm{R}_{\mathrm{ij}}(\mathrm{s})=\frac{\sum_{\mathrm{l}=0}^{\mathrm{K}-1}\left[\mathrm{~b}_{\mathrm{ij}}\right] \mathrm{s}^{\mathrm{l}}}{\sum_{\mathrm{l}=0}^{\mathrm{k}}\left[\mathrm{a}_{\mathrm{l}}\right] \mathrm{s}^{\mathrm{l}}}$

\section{NUMERICAL EXAMPLES:}

Ex.1. Let higher order the MIMO system be

$\mathrm{G}(\mathrm{S})=\frac{1}{\mathrm{D}(\mathrm{s})}\left[\mathrm{g}_{11} \mathrm{~g}_{12}\right]$

$G_{11}=\frac{3 S^{5}+10 S^{4}+122 \Phi^{3}+549 \Phi^{2}+1186 \Phi+8400}{S^{6}+41 S^{5}+57 S^{4}+349 S^{3}+1006 \bigotimes^{2}+1810 \Phi+600 C}$

$G_{12}=\frac{2 S^{5}+72 S^{4}+932 S^{3}+531 \Phi^{2}+1280 \Phi+9000}{S^{6}+41 S^{5}+57 S^{4}+349 \Phi^{3}+1006 \Phi^{2}+1810 \Phi+6000}$

Using the suggested procedure,

The $4^{\text {th }}$ order reduced Denominator polynomial is obtained as,

$\mathrm{D}_{4}(\mathrm{~S})=552.831 \mathrm{~S}^{4}+3263.61 \mathrm{~S}^{3}+10048.86 \mathrm{~S}^{2}+18100 \mathrm{~S}+6000$

The reduced Numerator polynomial is

$\mathrm{N}_{4}(\mathrm{~S})=1141.46 \mathrm{~S}^{3}+5485.9 \mathrm{~S}^{2}+11860 \mathrm{~S}+8400$

The Reduced order system is

$\mathrm{R}_{11}^{4}(\mathrm{~S})=$

$1141.46 S^{3}+5485.9 S^{2}+11860 S+8400$

$552.83 S^{4}+3263.61 S^{3}+10048.86 S^{2}+18100 S+6000$

$\mathrm{R}_{12}^{4}(\mathrm{~S})=$

$871.29 S^{3}+5304.119 S^{2}+12800 S+9000 \quad$ The step responses of the original high order and reduced order systems are compared in fig. 1 \& fig.2

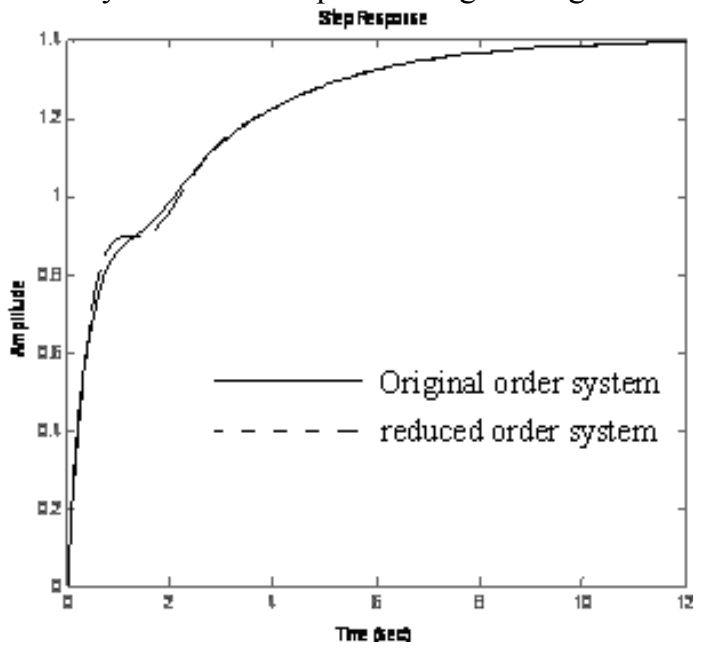

Fig.1.step response of the original and reduced order systems

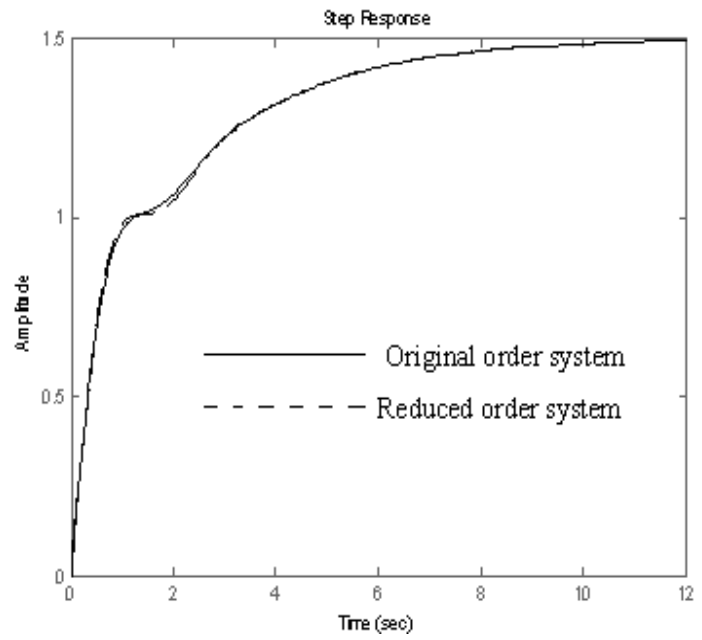

Fig.2.step response of the original and reduced order systems

Ex.2:

2. Let the MIMO higher order system be

$\mathrm{G}(\mathrm{S})=\frac{1}{\mathrm{D}(\mathrm{s})}\left[\begin{array}{ll}\mathrm{g}_{11} & \mathrm{~g}_{12}\end{array}\right]$

$\mathrm{G}_{11}(\mathrm{~S})=\frac{28 S^{3}+496 S^{2}+1800 S+2400}{2 S^{4}+36 S^{3}+204 S^{2}+360 S+240}$

$\mathrm{G}_{12}(\mathrm{~S})=\frac{12 S^{3}+528 S^{2}+1440 S+4320}{2 S^{4}+36 S^{3}+204 S^{2}+360 S+240}$ 
The reduced order models obtained by the suggested method

$$
\begin{aligned}
\mathrm{R}_{31}(\mathrm{~S}) & =\frac{490.2 S^{2}+1800 S+2400}{36 S^{3}+201.6 S^{2}+360 S+240} \\
\mathrm{R}_{32}(\mathrm{~S}) & =\frac{521.89 S^{2}+1440 S+4320}{36 S^{3}+201.64 S^{2}+360 S 239.99}
\end{aligned}
$$

The reduced order models obtained by using the RAM model [9]

$\mathrm{R}_{31}(\mathrm{~S})=\frac{352 S^{2}+1350 S+1800}{24 S^{3}+151 S^{2}+270 S+180}$

$\mathrm{R}_{32}(\mathrm{~S})=\frac{360 S^{2}+1080 S+3240}{24 S^{3}+151 S^{2}+270 S+180}$

The step response of the original high order and reduced order models are obtained by the suggested procedure and RAM [1] are compared in fig. 3 \& fig. 4 .

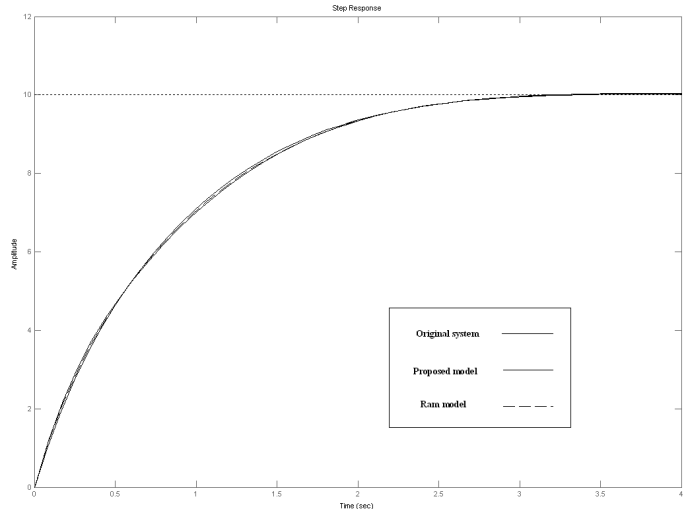

Fig.3.Comparision of responses

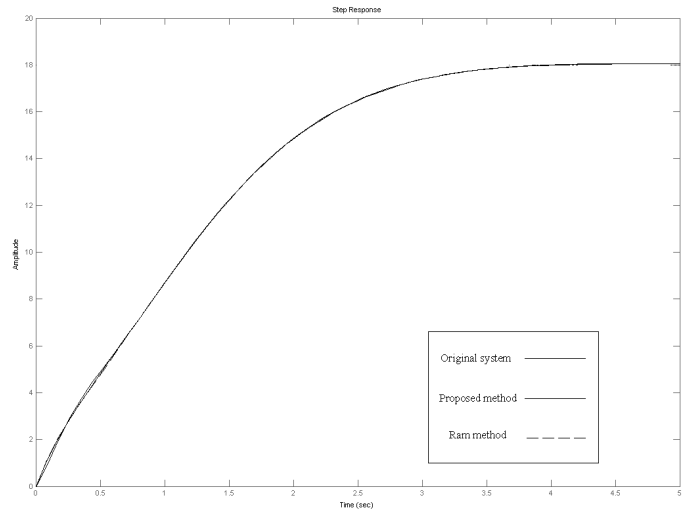

Fig.4.Comparision of responses

\section{CONCLUSIONS:}

In this paper a mixed method has been suggested for the reduction of Linear high order MIMO system. This method is simple and efficient and gives a stable reduced order model for a stable high order MIMO system. The reliability \& advantages of the suggested method have been illustrated by the examples. This procedure is dependent on the interlacing property of polynomials and matching of coefficients of high order system and reduced order model. The main property of this method is the retention of the stability of original system in their reduced morel is guaranteed. The matching of coefficients gives better approximation of the time responses of original system and model. This method is digital computer oriented.

\section{REFERENCES:}

[1] Hutton, M.F and Friedland,B., "Routh Approximation for reducing order of linear time invariant systems", IEEE Trans. On Automatic Control, Vol.20, 1975, PP.329-337.

[2] Shieh,L.S and Goldman ,M.J, "Continued Fraction Expansion and Inversion of Cauer Third form", IEEE Trans. Circuits and Systems, May 1994, PP.341-345.

[3] Pal.J, "Stable Reduced order Pade Approximates using the Routh- Hurwitz Array", Electronic letters, Vol.15, No.8, April 1979, PP.225-226.

[4] Shamash, Y. "Linear System Reduction by Pade Approximation to allow retention of Dominant modes", International Journal of Control, Vol.21, 1975, PP.258-272.

[5] Bendekal DV.Papadopoulos D.P, "The Moment and Pade approximate method Applied to the order reduction of MIMO Linear system”, Journal of Franklin. Vol .329.No.3, 1992.

[6] Taiwo O, "the simplification of Multivariable pade aapproximation", International conference on control and Modeling Tehron, Iran,1990.

[7] Chen C.F., "model reduction of multi variable Control systems by continued Fraction", International journal of control, Vol.20, No.2, 1974.

[8] Sinha .N.K "Reduction of multivariable system", Electrical letter Vol.16,No.20,1980 